4 Abstract

7 Polyethylene acetabular components are commonplace in hip arthroplasty. Highly cross-linked 8 polyethylene (HXLPE) has lower wear than ultra-high molecular weight polyethylene (UHMWPE).

9 Evidence suggests wear particles induce inflammation causing peri-prosthetic osteolysis contributing

10 to implant loosening with wear rates of $0.05 \mathrm{~mm} / \mathrm{yr}$ considered safe. We aimed to compare incidence

11 and volume of peri-acetabular osteolysis between HXLPE and UHMWPE using computed tomography

12 (CT).

13 Methods

14 Initially 54 hips in 53 patients were randomized to HXLPE or UHMWPE acetabular liner. At 10 years 39 15 hips in 38 patients remained for radiostereometric analysis (RSA) demonstrating significantly lower 16 wear in the HXLPE group. At 12 years 14 hips in 13 patients were lost to follow-up leaving 25 hips for 17 CT assessment. Images were reconstructed to detect osteolysis and where identified, areas were 18 segmented and volumised.

\title{
19 Results
}

20 Osteolysis was observed in eight patients, seven from the UHMWPE group and only one from the 21 HXLPE group (Fisher's Exact $p=0.042$ ). There was no correlation between amount of polyethylene 22 wear and osteolysis volume however, RSA measured wear rate in patients with osteolysis from both 23 groups was significantly higher than overall average wear rate.

\section{Conclusion}

25 This data demonstrates lower incidence of peri-acetabular osteolysis in the HXLPE group of a small 26 cohort. Whilst numbers are too low to estimate causation, in the context of lower wear in the HXLPE 27 group this finding supports the hypothesis that HXLPE may not elevate osteolysis risk and hence does 28 not suggest HXLPE wear particles are more biologically active than those generated by earlier 29 generations of polyethylene.

30

31 Keywords

32

33 Primary Total Hip Arthroplasty, Polyethylene wear, Peri-prosthetic Osteolysis, Highly Cross-linked 34 Polyethylene 
38 Osteolysis caused by polyethylene wear debris is accepted as the major cause of aseptic loosening and implant failure in total hip arthroplasty (THA)[1,2]. Revision surgery as a treatment for this failure constitutes a significant cause of morbidity and mortality[3]. Historically osteolysis has been identified using plain radiograph based measures, notably the Charnley[4], Devane[5] and Pederson[6] methods. The sensitivity of these measures is intrinsically limited, due to the two-dimensional nature of the images, and therefore depends significantly on lesion location with overall sensitivity having been shown to be only $41.5 \%$ [7]. More recently efforts have been made to investigate the use of cross sectional imaging techniques including computed tomography (CT) and magnetic resonance imaging (MRI) with CT giving greater sensitivity for detection of osteolysis when compared to radiography[8,9]. Walde et al. investigated radiography, CT and MRI for identification of osteolytic lesions and their results supported the poor sensitivity of radiography as well as showing CT to be marginally superior to MRI due to the greater interpretative challenges associated with beam hardening due to metal artefact in MRI techniques[10].

Polyethylene has been used continuously in THA since its inception and has proved a reliable material. Historically, femoral bearings are either metal or ceramic, both of which are considerably harder than polyethylene. Over the lifespan of implants this causes acetabular component wear, increasing the likelihood of failure[11]. One mechanism for this failure results from the generation of wear particles that induce an inflammatory reaction mediated by proinflammatory cytokines and upregulation of macrophages[12]. This inflammatory reaction has been causally linked with periprosthetic osteolysis seen in aseptic implant loosening[13].

To minimise wear and failure, the material properties of polyethylene have been modified[14,15]. The most recent advance has been the development of Highly Cross-Linked Polyethylene (HXLPE), which has been shown to have significantly superior ex vivo and in vivo wear when compared to UHMWPE[16,17]. Prospective studies have demonstrated a significant reduction in both linear wear and volumetric wear at 10 years post-implantation, when compared to conventional UHMWPE.

The process of osteolysis is thought to result from the biological reaction generated by wear debris although it has also been shown to occur in the absence of identifiable wear debris[18]. This problem

68 has been well studied in ultra-high molecular weight polyethylene (UHWMPE), where the 69 concentration of polyethylene particles in tissue surrounding implants has been correlated directly 70 with wear volume[19]. It therefore follows that implants demonstrating less wear should generate 71 less wear debris and hence fewer instances of osteolysis. However, this may not be the case for every type of polyethylene, as in vitro studies have demonstrated that HXLPE particles may be more

73 bioreactive. Hence, lower volumes may be required to generate an inflammatory response[8,20]. 
Aseptic loosening caused by osteolysis has been well reported using plain radiograph methods in earlier generations of polyethylene[21]. A systematic review of wear and osteolysis outcomes of HXLPE revealed an 87\% lower risk of osteolysis with HXLPE[22].

In 2001 we recruited patients to a double-blind Randomised Control Trial, with the aim of measuring the long-term wear of HXLPE vs UHMWPE. This trial has reported radiostereometric analysis (RSA) measured linear and volumetric polyethylene wear at 2[23], 3[24], 7[25] and 10 years[16] and demonstrated that HXLPE has an order of magnitude lower wear than UHMWPE. This cohort provides a unique opportunity to study the long-term association between osteolysis and volumetric wear.

84 Therefore the aim of this study was to investigate and compare the incidence and volume of periacetabular osteolysis between UHMWPE and HXLPE using CT in order to identify any lesions of volumes that may be too small for identification using plain radiography.

\section{Materials \& Methods}

In the original cohort fifty-four hips, in fifty-three patients, with a diagnosis of osteoarthritis, were recruited from the waiting list for arthroplasty. Informed consent was gained from all patients that met the inclusion criteria. All patients received THA using cemented, collarless, tapered and polished femoral stems (Zimmer CPT) with 28mm Cobalt-Chromium head and cementless Trilogy (Zimmer) acetabular shell. Patients were allocated either conventional UHMWPE Trilogy liner or Longevity HXLPE acetabular liner at random ( $n=27$ for each group) using computerised randomisation software with stratification for age and sex. The Longevity HXLPE is manufactured from 1050 GUR resin using 10 MRad electron beam irradiation, remelting heat stabilisation and gas plasma sterilisation. All components used were manufactured by Zimmer (Warsaw, IN, USA). Baseline cohort demographics are shown in table 1.

Ethical approval was granted (REC Reference: C01.067), to amend the trial to investigate patients

102 from this cohort using CT to identify peri-prosthetic osteolysis. Fifty-three patients were initially

103 recruited (54 hips) and 38 patients remained (39 hips) at the 10-year assessment. From this cohort 13

104 patients (14 hips) were lost to follow-up (two deceased, three too unwell to attend, four withdrew 105 from the study and we lost contact with five). Figure 1 shows the Consort Flow-Chart.

107 Patients were recalled at minimum 12 years post surgery for CT of the hip. Details of the cohort at 12

108 years are shown in table 2 . All scans were performed using the same machine; a GE LightSpeed VCT

10964 Slice. All scans used the following image acquisition settings: rotation time $0.7 \mathrm{sec}$, slice thickness $110 \quad 0.625 \mathrm{~mm}$, fixed kv 120, pitch 0.969:1, noise index 28, auto ma between 120-600, large FOV. Image 111 sequence reformats were performed at $3 \mathrm{~mm}$ depth using the bony window in the three anatomical 
112 planes (axial, coronal and sagittal). Images were acquired in the Digital Imaging and Communications

113 in Medicine (DICOM) format.

115 All images were analysed using three dimensional multiplanar reconstruction views in OsiriX 64-Bit

116 software to identify areas of osteolysis. Osteolysis was defined as areas of lucency seen within the

117 bone where no evidence of trabeculae could be seen and there was evidence of cortication around

118 the lucent area (figure 2). Once areas of osteolysis had been identified we performed segmentation

119 and volumisation of the regions of interest using ITK-SNAP (www.itksnap.org) software[26] (figure 3).

121 Our RSA system has been shown to be accurate to less than $0.1 \mathrm{~mm}$ and has been used to assess this

122 cohort at 3, 6 and 12 months and 2, 3, 5, 7 and 10 years post surgery. This data has been reported and

123 has generated mean total and annualised linear penetration and volumetric wear rate for each group

124 at 10 years post surgery[16].

125

126 RSA analysis of this cohort has previously demonstrated a lower volumetric wear in the HXLPE group.

127 The findings from volumisation of areas of osteolysis seen on CT images were then plotted against the

128 prior RSA derived wear data to determine whether there was a relationship between polyethylene

129 wear and volume of osteolysis.

130

\section{Statistical Analysis}

133 The data were analysed for distribution. Pearson's chi-squared test was used to compare incidence of 134 osteolysis between groups with Fisher's exact test adjustment due to the low number of 135 observations. A p value of $<0.05$ was considered significant. Linear regression was used to assess the 136 relationship between polyethylene wear and volume of osteolysis. Analyses were performed using 137 Stata 13 (Stata Corp., Collage Station, TX).

138

\section{Results}

141 No patients in this study group had undergone revision surgery. The patients were followed up at 142 mean 12.2 years ( 11.8 to 12.5 ). Of these $52 \%$ were male and $48 \%$ were female with an average age at 143 follow up of 74.5 years $(59.9-87.3)$. Overall, osteolysis was observed on CT in eight patients, of 144 whom, seven were in the UHMWPE group and only one was in the HXLPE group (figure $4 \& 5$ ). The 145 observed difference in incidence of osteolysis was statistically significant: Pearson's Chi-Squared $146 p=0.030$, Fisher's Exact $p=0.042$. 
148 The volume of osteolysis in the patient from the HXLPE group was $101.1 \mathrm{~mm}^{3}$ whilst in the UHMWPE

149 group osteolysis was identified in seven patients with mean volume $1515.1 \mathrm{~mm}^{3}$ (SD $1920.6 \mathrm{~mm}^{3}$,

150 range $71.0-5169.0 \mathrm{~mm}^{3}$ ). Volumes for all patients shown in table 3.

152 The RSA measured wear data from this cohort has been reported and showed linear wear in the 153 UHMWPE group was $0.03 \mathrm{~mm} / \mathrm{yr}$ vs. $0.003 \mathrm{~mm} / \mathrm{yr}$ in the HXLPE group and volumetric wear between 1

$154 \& 10$ years in the UHMWPE group was $98 \mathrm{~mm}^{3}$ vs. $14 \mathrm{~mm}^{3}$ in the HXLPE group.

156 The RSA measured wear rate in patients with osteolysis from both groups was significantly higher 157 than the average wear rate which was demonstrated in each of the groups overall. The linear wear 158 rate seen in the patients with identified osteolysis from the UHMWPE group was $0.047 \mathrm{~mm} / \mathrm{yr}$ whilst 159 the wear rate for the patient in the HXLPE group was $0.014 \mathrm{~mm} / \mathrm{yr}$.

161 For patients with evidence of osteolysis, their individual wear measurements were plotted against 162 their osteolysis volumes and a line of best fit applied (figure 6). The $R^{2}$ value for the line was 0.0635 163 indicating no correlation between amount of polyethylene wear and osteolysis volume. When 164 osteolysis vs. wear was plotted by group for all patients (figure 5), it is clear that osteolysis was not seen in the cases with the highest polyethylene wear.

\section{Discussion}

169 The aim of this study was to investigate the incidence and volume of osteolysis in THA using CT and to further investigate the relationship of osteolysis with the RSA measured polyethylene wear rate. We

171 compared incidence and volume of osteolysis between patients receiving UHMWPE and HXLPE and

172 also correlated this with RSA-derived 10-year wear data.

174 To our knowledge this study represents the first report in the literature of a comparison of CT 175 measured osteolysis with RSA measured wear data in a randomised cohort beyond 10 years post 176 surgery. Results from the original cohort of patients has shown that the polyethylene wear rate in the 177 group of patients receiving UHMWPE was 10 times greater than in those receiving HXLPE (annual 178 UHMWPE wear rate $0.03 \mathrm{~mm} / \mathrm{yr}$ compared with $0.003 \mathrm{~mm} / \mathrm{yr}$ in HXLPE)[16]. At minimum 12 years 179 following surgery CT examination has shown a dramatically higher incidence of osteolysis in the 180 UHMWPE group despite a mean wear rate well below expected.

182 In this cohort both groups have shown a mean linear wear rate significantly below $0.05 \mathrm{~mm} / \mathrm{yr}$, the 183 lowest threshold level identified by Dumbleton et al. for cementless hips[21] but in spite of this we 184 have still identified osteolysis. It has been shown that higher rates of polyethylene wear causes higher 185 rates of osteolysis[27]. Indeed, in their review, Dumbleton et al. showed that the rate of wear below 
which osteolysis is uncommon was $0.1 \mathrm{~mm} / \mathrm{yr}$ and went on to suggest osteolysis is almost absent with wear rate $<0.05 \mathrm{~mm} / \mathrm{yr}[21]$ in small head size of $22.25 \mathrm{~mm}$. More recent implants use larger head sizes, up to $36 \mathrm{~mm}$, where a lower linear wear rate will account for a larger volume of wear and hence generate equal or greater wear debris. Critically, all patients in whom we identified osteolysis had an individual wear rate well below $0.05 \mathrm{~mm} / \mathrm{yr}$, even in the UHMWPE group. All patients in this cohort received femoral head bearings measuring $28 \mathrm{~mm}$ and since calculation of wear rate was based upon

192 linear penetration measurement it is possible that volumetric wear has been underestimated. 193 Therefore an osteolysis threshold of $0.05 \mathrm{~mm} /$ year may be too high and the wear threshold may, in truth, be rather lower than originally suggested by Dumbleton et al.

Peri-prosthetic osteolysis is accepted as the major factor limiting prosthetic joint survival[28]. It has been shown that UHMWPE causes a cellular receptor-mediated response to wear particles which upregulate toll-like receptors $1,2 \& 4[29]$. HXLPE has been proven to have a superior wear profile than the prior generation of UHMWPE in this cohort[16,25], and other studies[30,31], however some wear debris generation is inevitable. Polyethylene particles generated by HXLPE are most commonly sized between 0.1-1.0 micron[20] and particles in this size range have been shown, in murine models, to be more bio-reactive and therefore more likely to influence osteolysis. This is not supported by the lower incidence of osteolysis in our cohort. In turn this may suggest the volume of polyethylene debris generated, and the inflammatory response it initiates, is the prominent factor in osteolysis rather than the size of the particles. This is supported by evidence showing that as volumetric wear rate increases the incidence of osteolysis and revision rates increases[32] as well as no increased bioactivity of HXLPE particles in vitro[33].

Another mechanism in the development of osteolysis is fluid pumping. It has been suggested that cyclical joint loading can induce a pumping effect, leading to pressure wave propagation to the

211 interfaces. The pressure alone may induce osteolysis, more likely it may transport particles to the

212 retroacetabular space[34]. Many implant related variables have been implicated in this process

213 including metal finish, liner thickness and component gap with in vitro studies showing pressure 214 fluctuations can be minimised by tight conformity of implants[35]. Whilst this remains a

215 consideration, it is not one our study was designed to address.

217 CT has been shown to be more sensitive than radiographic measures[36,37] with an accuracy[38] in 218 identifying osteolysis of around 96\%[9]. It has been suggested that a direct communication pathway 219 between the joint and osteolysis lesion must exist to define osteolysis[8,39] however we did not 220 observe this in all cases of osteolysis identified in this cohort. A 2014 RCT comparing solid back versus 221 cluster hole acetabular shells demonstrated no difference in incidence of osteolysis between groups 222 supporting our suggestion that this is not a critical element of peri-prosthetic acetabular osteolysis 223 generation[13]. In a similar study to ours Leung et al. recalled $33 \%$ of patients (76 of 236 ) originally 
224 enrolled in an RCT comparing conventional and cross-linked polyethylene and used CT to investigate

225 for osteolysis. Using a similar protocol they found osteolysis in $28 \%$ of patients with conventional

226 polyethylene and $8 \%$ of patients with cross-linked polyethylene acetabular components[8]. We have

227 demonstrated comparable results at beyond 10 years follow-up duration with a higher rate of recall.

229 The principle limitation of this study is loss to follow-up. This is unsurprising given the age of patients

230 (Mean 64.6 years) at baseline and the length of follow-up. Whilst this raises the risk of sampling bias it

231 is worth noting that the mean life expectancy for people aged 65 in England 15 years ago, at the time

232 of initial recruitment to this study, was 16.13 years for men and 19.23 years for women[40]. We

233 therefore believe this is unlikely to be a major issue given that the demographics of both groups are

234 similar. Another limitation is the definition of osteolysis; we have used previously published analysis

235 methodology and definitions of osteolysis on CT, however due to the relative novelty of using CT to

236 identify osteolysis there is no established definition or technique for identification. In view of this we

237 only classified areas of osteolysis that were clearly corticated. We also do not know whether

238 osteolysis on imaging will progress or is likely to result in failure. CT has been shown to be useful in

239 guiding treatment of osteolysis but volume was not directly correlated with implant failure[41]

240 meaning our measures represent a surrogate marker rather than a true prediction of revision. Finally,

241 although we have examined for osteolysis two years later than the wear assessment we feel this is

242 unlikely to make a significant difference to the results due to the very low wear rate seen over the

243 preceding decade.

245 This data suggests a lower incidence of peri-acetabular osteolysis in patients receiving HXLPE

246 acetabular liners in a small cohort. Whilst the numbers are too low to estimate causation, in the

247 context of lower wear in the HXLPE group this finding supports the hypothesis that use of HXLPE

248 liners may not elevate the risk of osteolysis and hence wear particles generated by HXLPE may be no

249 more biologically active than those generated from earlier generations of polyethylene. This study

250 represents an interesting finding that could be expanded by combining patients from a number of

251 cohorts but this may increase bias resulting from variations in implants.

\section{References}

255 [1] Harris WH. The problem is osteolysis. Clin Orthop Relat Res 1995:46-53.

256 [2] Mall N a, Nunley RM, Zhu JJ, Maloney WJ, Barrack RL, Clohisy JC. The incidence of acetabular osteolysis in young patients with conventional versus highly crosslinked polyethylene. Clin Orthop Relat Res 2011;469:372-81. doi:10.1007/s11999-010-1518-y.

[3] Berstock JR, Beswick AD, Lenguerrand E, Whitehouse MR, Blom AW. Mortality after total hip replacement surgery: A systematic review. Bone Joint Res 2014;3:175-82. doi:10.1302/20463758.36.2000239.

[4] Griffith MJ, Seidenstein MK, Williams D, Charnley J. Socket wear in Charnley low friction arthroplasty of the hip. Clin Orthop Relat Res n.d.:37-47. 
[5] Devane PA, Horne JG. Assessment of polyethylene wear in total hip replacement. Clin Orthop Relat Res 1999:59-72.

[6] Pedersen DR, Brown TD, Hillis SL, Callaghan JJ. Prediction of long-term polyethylene wear in

[7] Claus AM, Engh CA, Sychterz CJ, Xenos JS, Orishimo KF, Engh C a. Radiographic definition of

[8] Leung SB, Egawa H, Stepniewski A, Beykirch S, Engh CA, Engh C a. Incidence and volume of pelvic osteolysis at early follow-up with highly cross-linked and noncross-linked polyethylene. J Arthroplasty 2007;22:134-9. doi:10.1016/j.arth.2007.04.006.

[9] Stamenkov R, Howie D, Taylor J, Findlay D, McGee M, Kourlis G, et al. Measurement of bone defects adjacent to acetabular components of hip replacement. Clin Orthop Relat Res 2003:117-24. doi:10.1097/01.blo.0000069001.16315.f4.

[10] Walde T a, Weiland DE, Leung SB, Kitamura N, Sychterz CJ, Engh CA, et al. Comparison of CT, $\mathrm{MRI}$, and radiographs in assessing pelvic osteolysis: a cadaveric study. Clin Orthop Relat Res 2005:138-44. doi:10.1097/01.blo.0000164028.14504.46.

[11] Endo MM, Barbour PS, Barton DC, Fisher J, Tipper JL, Ingham E, et al. Comparative wear and wear debris under three different counterface conditions of crosslinked and non-crosslinked ultra high molecular weight polyethylene. Biomed Mater Eng 2001;11:23-35.

[12] Holt G, Murnaghan C, Reilly J, Meek RMD. The biology of aseptic osteolysis. Clin Orthop Relat Res 2007;460:240-52. doi:10.1097/BLO.0b013e31804b4147.

[13] Blakeney WG, Khan H, Khan RJK. Cluster Hole Versus Solid Cup in Total Hip Arthroplasty: A Randomized Control Trial. J Arthroplasty 2014. doi:10.1016/j.arth.2014.08.027.

[14] Engh CA, Stepniewski AS, Ginn SD, Beykirch SE, Sychterz-Terefenko CJ, Hopper RH, et al. A Randomized Prospective Evaluation of Outcomes After Total Hip Arthroplasty Using Crosslinked Marathon and Non-cross-linked Enduron Polyethylene Liners. J Arthroplasty 2006;21:17-25. doi:10.1016/j.arth.2006.05.002.

[15] Manning DW, Chiang PP, Martell JM, Galante JO, Harris WH. In vivo comparative wear study of traditional and highly cross-linked polyethylene in total hip arthroplasty. J Arthroplasty 2005;20:880-6. doi:10.1016/j.arth.2005.03.033.

[16] Glyn-Jones S, Thomas GER, Garfjeld-Roberts P, Gundle R, Taylor A, McLardy-Smith P, et al. The John Charnley Award: Highly Crosslinked Polyethylene in Total Hip Arthroplasty Decreases Long-term Wear: A Double-blind Randomized Trial. Clin Orthop Relat Res 2014. doi:10.1007/s11999-014-3735-2.

[17] Johanson PE, Digas G, Herberts P, Thanner J, Kärrholm J. Highly crosslinked polyethylene does not reduce aseptic loosening in cemented THA 10-year findings of a randomized study. Clin Orthop Relat Res 2012;470:3083-93. doi:10.1007/s11999-012-2400-x.

[18] van der Vis H, Aspenberg P, de Kleine R, Tigchelaar W, van Noorden CJ. Short periods of oscillating fluid pressure directed at a titanium-bone interface in rabbits lead to bone lysis. Acta Orthop Scand 1998;69:5-10. doi:10.3109/17453679809002345.

[19] Kobayashi A, Freeman MA, Bonfield W, Kadoya Y, Yamac T, Al-Saffar N, et al. Number of polyethylene particles and osteolysis in total joint replacements. A quantitative study using a tissue-digestion method. J Bone Joint Surg Br 1997;79:844-8.

[20] Ingram JH, Stone M, Fisher J, Ingham E. The influence of molecular weight, crosslinking and counterface roughness on TNF-alpha production by macrophages in response to ultra high molecular weight polyethylene particles. Biomaterials 2004;25:3511-22. doi:10.1016/j.biomaterials.2003.10.054.

[21] Dumbleton JH, Manley MT, Edidin AA. A literature review of the association between wear rate and osteolysis in total hip arthroplasty. J Arthroplasty 2002;17:649-61. doi:10.1054/arth.2002.33664. 
[22] Kurtz SM, Gawel H a., Patel JD. History and systematic review of wear and osteolysis outcomes for first-generation highly crosslinked polyethylene. Clin. Orthop. Relat. Res., vol. 469, 2011, p. 2262-77. doi:10.1007/s11999-011-1872-4.

[23] Glyn-Jones S, Isaac S, Hauptfleisch J, McLardy-Smith P, Murray DW, Gill HS. Does Highly CrossLinked Polyethylene Wear Less Than Conventional Polyethylene in Total Hip Arthroplasty?. A Double-Blind, Randomized, and Controlled Trial Using Roentgen Stereophotogrammetric Analysis. J Arthroplasty 2008;23:337-43. doi:10.1016/j.arth.2006.12.117.

[24] Glyn-Jones S, McLardy-Smith P, Gill HS, Murray DW. The creep and wear of highly cross-linked polyethylene: a three-year randomised, controlled trial using radiostereometric analysis. J Bone Joint Surg Br 2008;90:556-61. doi:10.1302/0301-620X.90B5.20545.

[25] Thomas GER, Simpson DJ, Mehmood S, Taylor A, McLardy-Smith P, Gill HS, et al. The sevenyear wear of highly cross-linked polyethylene in total hip arthroplasty: a double-blind, randomized controlled trial using radiostereometric analysis. J Bone Joint Surg Am 2011;93:716-22. doi:10.2106/JBJS.J.00287.

[26] Yushkevich P a, Piven J, Hazlett HC, Smith RG, Ho S, Gee JC, et al. User-guided 3D active contour segmentation of anatomical structures: significantly improved efficiency and reliability. Neuroimage 2006;31:1116-28. doi:10.1016/j.neuroimage.2006.01.015.

[27] Livingston BJ, Chmell MJ, Spector M, Poss R. Complications of total hip arthroplasty associated with the use of an acetabular component with a Hylamer liner. J Bone Joint Surg Am 1997;79:1529-38.

[28] Abu-Amer Y, Darwech I, Clohisy JC. Aseptic loosening of total joint replacements: mechanisms underlying osteolysis and potential therapies. Arthritis Res Ther 2007;9 Suppl 1:S6. doi:10.1186/ar2170.

[29] Paulus a C, Frenzel J, Ficklscherer a, Roßbach BP, Melcher C, Jansson V, et al. Polyethylene wear particles induce TLR 2 upregulation in the synovial layer of mice. J Mater Sci Mater Med 2014;25:507-13. doi:10.1007/s10856-013-5095-y.

[30] Muratoglu OK, Bragdon CR, O\&apos;Connor DO, Jasty M, Harris WH, Rizwan G, et al. Unified wear model for highly crosslinked ultra-high molecular weight polyethylenes (UHMWPE). Biomaterials 1999;20:1463-70. doi:10.1016/S0142-9612(99)00039-3.

[31] McKellop H, Shen FW, Lu B, Campbell P, Salovey R. Development of an extremely wearresistant ultra high molecular weight polyethylene for total hip replacements. J Orthop Res 1999;17:157-67. doi:10.1002/jor.1100170203.

[32] Oparaugo PC, Clarke IC, Malchau H, Herberts P. Correlation of wear debris-induced osteolysis and revision with volumetric wear-rates of polyethylene: a survey of 8 reports in the literature. Acta Orthop Scand 2001;72:22-8. doi:10.1080/000164701753606644.

[33] Galvin a L, Jennings LM, Tipper JL, Ingham E, Fisher J. Wear and creep of highly crosslinked polyethylene against cobalt chrome and ceramic femoral heads. Proc Inst Mech Eng H 2010;224:1175-83. doi:10.1243/09544119JEIM741.

[34] Walter WL, Walter WK, O'Sullivan M. The Pumping of Fluid in Cementless Cups with Holes. J Arthroplasty 2004;19:230-4. doi:10.1016/j.arth.2003.10.005.

[35] Kurtz SM, Harrigan TP, Herr M, Manley MT. An in vitro model for fluid pressurization of screw holes in metal-backed total joint components. J Arthroplasty 2005;20:932-8. doi:10.1016/j.arth.2004.11.003.

[36] Leung S, Naudie D, Kitamura N, Walde T, Engh CA. Computed tomography in the assessment of periacetabular osteolysis. J Bone Joint Surg Am 2005;87:592-7. doi:10.2106/JBJS.D.02116.

[37] Claus AM, Totterman SM, Sychterz CJ, Tamez-Peña JG, Looney RJ, Engh C a. Computed tomography to assess pelvic lysis after total hip replacement. Clin Orthop Relat Res 2004:16774. doi:10.1097/01.blo.0000129345.22322.8a.

[38] Puri L, Wixson RL, Stern SH, Kohli J, Hendrix RW, Stulberg SD. Use of helical computed tomography for the assessment of acetabular osteolysis after total hip arthroplasty. J Bone 
Joint Surg Am 2002;84-A:609-14.

[39] Kitamura N, Naudie DDR, Leung SB, Hopper RH, Engh CA. Diagnostic features of pelvic osteolysis on computed tomography: the importance of communication pathways. J Bone Joint Surg Am 2005;87:1542-50. doi:10.2106/JBJS.D.02882.

[40] Life Expectancy at Birth and at Age 65 by Local Areas in England and Wales: 2012 to 2014. Off

370

[41] Yun HH, Shon WY, Hong SJ, Yoon JR, Yang JH. Relationship between the pelvic osteolytic volume on computed tomography and clinical outcome in patients with cementless acetabular components. Int Orthop 2011;35:1453-9. doi:10.1007/s00264-010-1132-3.

Table 1 - Cohort Demographics at Baseline

\begin{tabular}{l|l|l}
\hline Variable & HXLPE $(\mathbf{n = 2 7})$ & UHMWPE $(\mathbf{n = 2 7})$ \\
\hline Age (years), mean (range) & $68(52-76)$ & $67(51-76)$ \\
\hline Weight (kg), mean (range) & $79(49-117)$ & $82(75-108)$ \\
\hline Sex (male:female) & $11: 9$ & $9: 10$ \\
\hline
\end{tabular}

Table 2 - Cohort Demographics at 12 Year Follow Up

\begin{tabular}{l|l|l}
\hline Variable & HXLPE $(\mathbf{n = 1 1 )}$ & UHMWPE $(\mathbf{n = 1 4 )}$ \\
\hline Age (years), mean (range) & $74(60-83)$ & $75(60-87)$ \\
\hline Sex (male:female) & $5: 6$ & $8: 6$ \\
\hline
\end{tabular}

\section{Table 3 - Details of Osteolysis}

\begin{tabular}{c|c|c|c}
\hline Age & Sex & Liner & Volume $\left(\mathbf{m m}^{\mathbf{3}}\right)$ \\
\hline 71.5 & Male & HXLPE & 101 \\
\hline 65.2 & Female & UHMWPE & 255 \\
\hline 74.9 & Female & UHMWPE & 5169 \\
\hline 67.2 & Male & UHMWPE & 3726 \\
\hline 66.0 & Male & UHMWPE & 1082 \\
\hline 74.4 & Male & UHMWPE & 123 \\
\hline 74.5 & Male & UHMWPE & 180 \\
\hline 84.2 & Female & UHMWPE & 71 \\
\hline
\end{tabular}

